\title{
Ginsenoside Rg3 targets cancer stem cells and tumor angiogenesis to inhibit colorectal cancer progression in vivo
}

\author{
YU-CHEN TANG $^{1,2^{*}}$, YAN ZHANG $^{1 *}$, JIN ZHOU $^{2 *}$, QIAOMING ZHI $^{2 *}$, MENG-YAO WU $^{1}$, \\ FEI-RAN GONG ${ }^{3}$, MENG SHEN $^{1}$, LU LIU $^{1}$, MIN TAO $^{1,4}$, BAIRONG SHEN $^{5}$, DONG-MEI GU $^{6}$, \\ JIE $\mathrm{YU}^{6}$, MENG-DAN XU ${ }^{1}$, YUAN GAO ${ }^{1}$ and WEI LI ${ }^{1,4,5,7}$
}

\begin{abstract}
Departments of ${ }^{1}$ Oncology, ${ }^{2}$ General Surgery, and ${ }^{3}$ Hematology, The First Affiliated Hospital of Soochow University, Suzhou, Jiangsu 215006; ${ }^{4}$ PREMED Key Laboratory for Precision Medicine, Soochow University, Suzhou, Jiangsu 215021; ${ }^{5}$ Center for Systems Biology, Soochow University, Suzhou, Jiangsu 215006; ${ }^{6}$ Department of Pathology, The First Affiliated Hospital of Soochow University, Suzhou, Jiangsu 215006; ${ }^{7}$ The Comprehensive Cancer Center, Suzhou Xiangcheng People's Hospital, Suzhou, Jiangsu 215000, P.R. China
\end{abstract}

Received June 10, 2017; Accepted October 24, 2017

DOI: $10.3892 /$ ijo.2017.4183

\begin{abstract}
Anti-angiogenic therapy has been successfully applied to treat colorectal cancer (CRC). Ginsenoside Rg3, derived from the Chinese herb ginseng, has anti-vascularization effects and can inhibit tumor growth and metastasis, and can sensitize cancer cells to chemotherapy. Therefore, in the present study, we investigated whether $\operatorname{Rg} 3$ could be appropriate for CRC treatment. Growth of CRC cells was assessed by an MTT (methyl thiazolyl tetrazolium) assay in vitro and using orthotopic xenograft models in vivo. mRNA expression was evaluated using real-time PCR. Protein levels were tested by western blotting, flow cytometry and immunohistochemistry. Migration was determined using a wound-healing assay. Stemness was further confirmed using a plate clone formation assay. We found that $\mathrm{Rg} 3$ repressed the growth and stemness of CRC cells both in vitro and in vivo. $\operatorname{Rg} 3$ also impaired the migration of CRC cells in vitro. $\mathrm{Rg} 3$ downregulated the expressions of angiogenesis-related genes, and repressed the vascularization of CRC xenografts. In addition, $\operatorname{Rg} 3$ strengthened the cytotoxicity of 5-Fluorouracil and oxaliplatin against orthotopic xenografts in vivo. Moreover, $\mathrm{Rg} 3$ downregulated the expressions of $\mathrm{B} 7-\mathrm{H} 1$ and $\mathrm{B} 7-\mathrm{H} 3$, high expressions of which were associated with reduced overall survival (OS) of CRC patients. Hence, $\operatorname{Rg} 3$ not only
\end{abstract}

Correspondence to: Dr Wei Li or Dr Meng-Dan Xu, Department of Oncology, The First Affiliated Hospital of Soochow University, Suzhou, Jiangsu 215006, P.R. China

E-mail: liwei10@suda.edu.cn; dr_weili@163.com

E-mail: doctor_xmd@163.com; mengdanxu@suda.edu.cn

*Contributed equally

Key words: ginsenoside $\operatorname{Rg} 3$, colorectal cancer, cancer stem cells, tumor angiogenesis, antitumor immunity repressed the growth and stemness of CRC cells, but could also remodel the tumor microenvironment through repressing angiogenesis and promoting antitumor immunity. Therefore, $\mathrm{Rg} 3$ could be a novel therapeutic for the CRC treatment.

\section{Introduction}

Colorectal cancer (CRC), one of the most commonly registered cancers worldwide, is associated with high mortality, especially for advanced and metastatic patients (1). Although enormous efforts have been made in both basic and clinical research in the fight against CRC, there are more than one million new cases per year in the world. It is estimated that approximately 95,520 (colon cancer only) new cases and 50,260 (colon and rectal cancers combined) deaths from CRC will occur in the United States in 2017 (2,3). Although surgery can cure approximately half of the patients, it is reported that disease recurrence is nearly 50\% among patients with CRC who received resection (4).

Aberrant angiogenesis is an essential step in the progression of CRC, which provides nutrients and oxygen for the survival, growth and metastasis of the tumor cells (5). Anti-angiogenic therapy has been proved to be one of the most crucial and promising approaches to control tumor growth (6). The combination of anti-angiogenic therapy and chemotherapy has been well accepted as a first-line regimen for metastatic CRC (7).

Ginsenoside, $\operatorname{Rg} 3$, one of the major active components of ginseng, displays anti-angiogenesis ability $(5,8)$ and has been widely used in traditional medicine. $\mathrm{Rg} 3$ has been reported to exhibit antitumor effects in several types of cancer, including ovarian, breast and lung cancer $(9,10)$. Rg3 also repressed migration and induced apoptosis in CRC cells in vitro $(9,10)$.

Therefore, in the present study, we attempted to verify whether $\mathrm{Rg} 3$ could be applied to the treatment of CRC in orthotopic xenograft models; the mechanisms involved were also investigated. 


\section{Materials and methods}

Cell line and cultures. The human CRC cell lines, LoVo, SW620 and HCT116, were purchased from the American Type Culture Collection (ATCC; Manassas, VA, USA). Cells were maintained in Dulbecco's modified Eagle's medium (DMEM; Gibco, Grand Island, NY, USA) supplemented with $10 \%$ fetal calf serum (FCS; Hyclone Laboratories, Inc., Logan, UT, USA), $100 \mathrm{U} / \mathrm{m}$ penicillin and $100 \mathrm{mg} / \mathrm{ml}$ streptomycin. The cultures were incubated at $37^{\circ} \mathrm{C}$ in a humidified atmosphere with $5 \% \mathrm{CO}_{2}$. Cells were passaged every 2-3 days to obtain exponential growth.

Reagents. $\operatorname{Rg} 3$ was purchased from Shanghai Jinsui Bio-Technology Co., Ltd., (Shanghai, China), fluorouracil (5-FU) was purchased from Shanghai Xudong Haipu Pharmaceutical Co., Ltd., (Shanghai, China) and oxaliplatin was purchased from Jiangsu Hengrui Medicine Co., Ltd. (Lianyungang, China).

MTT assay. Cellular growth was evaluated by an MTT (methyl thiazolyl-tetrazolium) assay (11). Cells were seeded into 24-well tissue culture plates at $5 \times 10^{4}$ cells/well. After treatment, MTT (Sigma-Aldrich, St. Louis, MO, USA) was added to each well to a final concentration of $0.5 \mathrm{mg} / \mathrm{ml}$, followed by incubation at $37^{\circ} \mathrm{C}$ for $4 \mathrm{~h}$. The medium was then removed, and $800 \mu 1$ of dimethyl sulfoxide (DMSO) was added per well. The absorbance in each well was measured at $490 \mathrm{~nm}$ using a microplate enzyme-linked immunosorbent assay (ELISA) reader (Bio-Rad Laboratories, Hercules, CA, USA). The relative cell viability was calculated as follows: Relative cell viability $=($ mean experimental absorbance $/$ mean control absorbance) x $100 \%$.

Wound healing assay. Cells ( $1 \times 10^{4} /$ well) were seeded in 96-well plates and grown to confluence. The monolayer culture was artificially scraped/wounded with a sterile micropipette tip to create a denuded zone of constant width. Each well was washed with phosphate-buffered saline (PBS) twice to remove the detached cells. Cell migration to the wounded region was observed using an XDS-1B inverted microscope (MIC Optical and Electrical Instrument, Chongqing, China) and photographed (x40 magnification). Images were captured at $0,3,6,9$ and $12 \mathrm{~h}$ to monitor the wound healing process. The wound areas were measured using Image J (NIH, Bethesda, MA, USA).

Evaluation of protein levels. The protein levels of CD24, CD44 and EpCAM in colon cancer cells were measured by flow cytometry. Following treatment, the cells were harvested, fixed with $4 \%$ paraformaldehyde and were permeabilized using $0.1 \%$ Triton X-100. After washing with PBS three times, cells were incubated with anti-CD24 (FITC-conjugated; Santa Cruz Biotechnology, Inc., Santa Cruz, CA, USA), anti-CD44 (PE-conjugated; Santa Cruz Biotechnology), and anti-EpCAM (PerCP-cy5.5-conjugated; Santa Cruz Biotechnology) antibodies, respectively, for $30 \mathrm{~min}$ at $4^{\circ} \mathrm{C}$. Subsequently, the cells were analyzed using a Beckman Coulter FC500 flow cytometer (Beckman Coulter, Indianapolis, IN, USA).
Stemness evaluation of cancer cells. Cells were harvested, washed twice with $2 \%$ fetal bovine serum (FBS)/PBS solution, and resuspended in $100 \mu 1$ of $2 \% \mathrm{FBS} / \mathrm{PBS}$, before incubating with anti-CD24 (FITC-conjugated), anti-CD44 (PE-conjugated), and anti-EpCAM (PerCP-cy5.5-conjugated) antibodies for $30 \mathrm{~min}$ at $4^{\circ} \mathrm{C}$. Cells were then washed twice with $2 \%$ FBS/PBS solution, and resuspended in $500 \mu 1$ of $2 \%$ FBS/PBS before assessment on a Beckman Coulter FC500 flow cytometer (Beckman Coulter).

Plate clone formation assay. LoVo and HCT116 cells were used in this assay. LoVo cells were seeded at a density of 250 cells/well and HCT116 cells were seeded at a density of 500 cells/well in 24-well plates and treated with different concentrations of Rg3 3 days later. After treatment for 12 days, the cells were stained with $1 \%$ methylrosanilinium chloride and the numbers of visible colonies were counted. The relative clone formation ability was calculated as relative clone formation ability $=($ mean experimental clone number $/$ mean control clone number) x $100 \%$.

Real-time PCR. Total RNA was extracted using TRIzol reagent (Invitrogen, Carlsbad, CA, USA), according to the manufacturer's protocol. After spectrophotometric quantification, $1 \mu \mathrm{g}$ of total RNA in a final volume of $20 \mu \mathrm{l}$ was used for reverse transcription with a PrimeScript RT Reagent kit (Takara, Bio, Shiga, Japan), according to the manufacturer's protocol. Aliquots of cDNA corresponding to equal amounts of RNA were used to quantify the mRNA by real-time PCR using the LightCycler 96 Real-time Quantitative PCR Detection system (Roche Diagnostics, Indianapolis, IN, USA). The reaction system $(25 \mu \mathrm{l})$ contained the corresponding cDNA, forward and reverse primers, and the SYBR-Green PCR Master Mix (Roche Diagnostics). All data were analyzed using the expression of the $B 2 M$ gene as an internal standard. The specific primers are presented in Table I.

Nude mouse orthotopic tumor xenograft model and treatments. Four-week-old female BALB/c athymic nude mice were purchased from Shanghai SLAC Laboratory Animal Co., Ltd., (Shanghai, China) and received humane care according to the Soochow University Institutional Animal Care and Treatment Committee.

The orthotopic xenograft model was established as follows: Cells were injected into the left flanks of the mice in a total volume of $100 \mu 1\left(0.5 \times 10^{7}\right.$ cells), separately. Ten days later, when the tumors were palpable, the subcutaneous xenograft tumors were harvested and used to establish the orthotopic xenograft model, according to previous reports (12). In brief, the tumors were harvested and cut into pieces $(1.5 \mathrm{~mm}$ in diameter). A small midline incision was made and the sigmoideum part of the intestine was exteriorized. Serosa of the site where the tumor pieces were to be implanted was removed using an amyxis. Single pieces of the tumor were then implanted into the wall of the sigmoideum and fixed with surgical sutures. The intestine was returned to the abdominal cavity, and the abdominal wall was closed with surgical sutures. The animals were kept in a sterile environment. To validate the success of the orthotopic xenograft, exploratory laparotomy was performed on 5 randomly chosen mice 7 days after tumor inoculation. 
Table I. Primers used in the present study.

\begin{tabular}{|c|c|c|c|}
\hline Genes & Sense $\left(5^{\prime}-3^{\prime}\right)$ & Antisense $\left(5^{\prime}-3^{\prime}\right)$ & Product size (bp) \\
\hline \multicolumn{4}{|c|}{ Cancer stem cell markers } \\
\hline CD24 & CAGGGCAATGATGAATGAGAAT & CCTGGGCGACAAAGTGAGA & 233 \\
\hline CD44 & GTGATGGCACCCGCTATGTC & AACCTCCTGAAGTGCTGCTCC & 129 \\
\hline EpCAM & TAATCGTCAATGCCAGTGTACTTC & GCCATTCATTTCTGCCTTCAT & 100 \\
\hline \multicolumn{4}{|c|}{ Angiogenesis-related genes } \\
\hline ANG & CAAGAATGGAAACCCTCACAGA & AAATGGAAGGCAAGGACAGC & 246 \\
\hline ANGPT1 & AGAGGTCAGAAGAAAGGAGCAAG & GTGAGTCAGAATGGCAGCGAG & 109 \\
\hline ANGPT2 & AGAGGAACAAAGGACCGTGAAAG & CTGTCAGATTGCAGTGGGAAG & 91 \\
\hline CCL1 & TGGATGGGTTCAGAGGCAC & GCAGGGCAGAAGGAATGGT & 147 \\
\hline CCL13 & AGGAGAAGTGGGTCCAGAATTAT & СТСАААТАAАСТССАAАCCAGCAAC & 265 \\
\hline CCL5 & GAGAAGAAATGGGTTCGGGAGT & AGGACAAGAGCAAGCAGAAACAGGC & 109 \\
\hline CCL7 & GCTCAGCCAGTTGGGATTAAT & TCATGGCTTGTTTTCAGTTCAGTC & 164 \\
\hline COL18A & TCAGACCACGGCTCGATTTC & CTCAGCTCCCATTGCCTCA & 154 \\
\hline CSF3 & CCTTCGCCTCTGCTTTCCA & CGTTCTGCTCTTCCCTGTCTTT & 199 \\
\hline CXCL1 & CACCCCAAGAACATCCAAAGT & CCTTCAGGAACAGCCACCA & 210 \\
\hline CXCL2 & GCTTATTGGTGGCTGTTCCTG & ACACATTAGGCGCAATCCAG & 101 \\
\hline CXCL3 & GCCCAAACCGAAGTCATAGC & GAACCCTCGTAAGAAATAGTCAAAC & 271 \\
\hline CXCL5 & ACAGTGCCCTACGGTGGAAGT & CTCATCAAAGCAGGGAGTTCATA & 266 \\
\hline EGF & GGGTGACCGTTTGGGAGTT & ATCCACCACGTCGTCCATG & 335 \\
\hline PLG & GACTATCTGGTTTGTGGATGCGT & TTCTTCGTCCTCCTCACATTTT & 201 \\
\hline FGF-2 & CTGTCTGGTTTGCTGCTGTATCT & GGTTTCTGGGATTTGCTTTATTC & 95 \\
\hline FIGF & CATCCCATCGGTCCACTAGGT & CAGCCACCACATCGGAACA & 190 \\
\hline FLT4 & GCTGTGCCTGCGACTGTG & CGTGTCCTCGCTGTCCTTGT & 138 \\
\hline GM-CSF & ACACTGCTGCTGAGATGAATGA & AAAGGTGATAATCTGGGTTGCA & 218 \\
\hline IFNG & TCCAACGCAAAGCAATACATG & TTGCAGGCAGGACAACCAT & 137 \\
\hline IGF1 & GGTGGATGCTCTTCAGTTCGT & GCAATACATCTCCAGCCTCCTTAG & 182 \\
\hline IL10 & TGGTGAAGGAGGATCGCTAGA & CCTTGATGTCTGGGTCTTGGTT & 204 \\
\hline IL1A & TGACGACGCACTTGTAGCCAC & GCCAATGAAATGACTCССТCT & 111 \\
\hline IL1B & ATTTGAGTCTGCCCAGTTCCC & AАCСTTTCTGTTCCCTTTCTGC & 207 \\
\hline IL2 & CAGTAACCTCAACTCCTGCCAC & CTGGTGAGTTTGGGATTCTTGTA & 227 \\
\hline IL4 & ССССТCTGTTCTTCСТGCTAG & TGTCCTTCTCATGGTGGCTGT & 181 \\
\hline IL8 & CTGGGTGCAGAGGGTTGTG & ACTGGCATCTTCACTGATTCTTG & 98 \\
\hline KDR & CCCAATAATCAGAGTGGCAGTG & CATAGACATAAATGACCGAGGCC & 163 \\
\hline MMP1 & GCTGAAAGTGACTGGGAAACC & TCTTGGCAAATCTGGCGTGT & 166 \\
\hline PDFGB & GCTGTTGAGGTGGCTGTAGATG & GTCGTGGCTGGGTTGGAAT & 281 \\
\hline PECAM1 & AGGTCAGCAGCATCGTGGT & GTGAAGTTGGCTGGAGGTG & 136 \\
\hline PGF & AAGGGAGCTGCTGTCTGCG & CTTGCGGAGTCAGGAGCCCGTAGGT & 192 \\
\hline PIGF & ACTGTGCCTTGCTTATGTTTGTT & CCAAGCCATGCTCCTACAAAG & 137 \\
\hline PLAUR & GCCGGGCTGTCACCTATT & CCACATCCAGGCACTGTTCTTC & 132 \\
\hline TEK & TAACTATGACTGTGGACAAGGGAG & GGCCGAGGTGAAGAGGTTT & 221 \\
\hline TGFB 1 & CTGGCGATACCTCAGCAACC & CTAAGGCGAAAGCCCTCAAT & 126 \\
\hline THPO & TCTCAGACACTGCCGACATCA & GGGCTTTGGGTTTCAGGAGA & 112 \\
\hline TIMP1 & GGTTGTGGGACCTGTGGAAGTA & CCAAGATGTATAAAGGGTTCCAAG & 108 \\
\hline TIMP2 & CCCCTGTTCGCTTCCTGTATG & GCGTTCCACTCTGGGTCAAAT & 207 \\
\hline TPO & AAGCAAGCGCCTGGTGGA & CAGGAAGTTTGGAAAAAGACAGAAG & 156 \\
\hline VEGFA & CACCCACCCACATACATACATTT & ССТСССАAСТCAAGTCCACAG & 170 \\
\hline \multicolumn{4}{|c|}{ Internal control } \\
\hline $\mathrm{B} 2 \mathrm{M}$ & TCAAGAAGGTGGTGAAGCAG & AAGGTGGAGGAGTGGGTGTC & 112 \\
\hline
\end{tabular}


Table II. Clinicopathological features of 129 patients with metastatic CRC.

\begin{tabular}{|c|c|c|c|c|c|c|c|c|c|}
\hline \multirow[b]{2}{*}{ Clinicopathological features } & \multirow[b]{2}{*}{$\mathrm{n}$} & \multicolumn{4}{|c|}{$\mathrm{B} 7 \mathrm{H} 3$} & \multicolumn{4}{|c|}{ B7H1 } \\
\hline & & Low (n) & High (n) & $\chi^{2}$ & P-value & Low (n) & High (n) & $\chi^{2}$ & P-value \\
\hline \multicolumn{10}{|l|}{ Sex } \\
\hline Male & 53 & 28 & 25 & 0.574 & 0.449 & 23 & 30 & 1.066 & 0.302 \\
\hline Female & 76 & 35 & 41 & & & 40 & 36 & & \\
\hline \multicolumn{10}{|l|}{ Age (years) } \\
\hline$>56$ & 62 & 35 & 27 & 2.770 & 0.096 & 32 & 30 & 0.368 & 0.544 \\
\hline$\leq 56$ & 67 & 28 & 39 & & & 31 & 36 & & \\
\hline \multicolumn{10}{|l|}{ BMI } \\
\hline$>25$ & 65 & 32 & 33 & 0.008 & 0.928 & 28 & 37 & 1.740 & 0.187 \\
\hline$\leq 25$ & 64 & 31 & 33 & & & 35 & 29 & & \\
\hline \multicolumn{10}{|l|}{ Liver metastasis } \\
\hline No & 51 & 31 & 20 & 4.818 & 0.028 & 34 & 17 & 10.731 & 0.001 \\
\hline Yes & 78 & 32 & 46 & & & 29 & 49 & & \\
\hline
\end{tabular}

The mice were observed and weighed once per day during the study period. After 12 days, all mice were euthanized and the tumors were carefully resected and weighed. The tumor tissue was then formalin-fixed, paraffin-embedded, cut into $4-\mu \mathrm{m}$ sections and immunohistochemically stained.

Immunohistochemistry. The resection specimens were fixed in $10 \%$ buffered formalin and paraffin-embedded by routine processing. Sections were cut at a thickness of $4 \mu \mathrm{m}$, heated at $60^{\circ} \mathrm{C}$ for $30 \mathrm{~min}$, and then deparaffinized and hydrated through a series of xylene and alcohol baths. The slides were microwaved in antigen retrieval solution (citrate buffer, pH 6.0 , containing $0.3 \%$ trisodium citrate and $0.04 \%$ citric acid) for $5 \mathrm{~min}$. After replenishment of this solution, the slides were microwaved again for $5 \mathrm{~min}$, and then allowed to cool for $20 \mathrm{~min}$. The sections were then rinsed in PBS and immersed in $3 \% \mathrm{H}_{2} \mathrm{O}_{2}$ for 15 min to block the endogenous peroxidase activity. Thereafter, the sections were incubated with $10 \%$ bovine serum albumin (BSA) at room temperature for $1 \mathrm{~h}$ to block non-specific antibodies. Immunohistochemical staining was performed using mouse anti-Ki-67 antibody (GM724029; GeneTech, Shanghai, China), rabbit anti-CD24 antibody (ab202963; Abcam,Cambridge, UK), rabbit anti-CD44 antibody (ab157107; Abcam), rabbit anti-EpCAM antibody (ab71916; Abcam), rabbit anti-B7-H1 antibody (ab205921; Abcam), mouse anti-B7-H3 antibody (ab105922; Abcam and rabbit anti-CD34 antibody (ab81289; Abcam) at room temperature for $2 \mathrm{~h}$. After incubation with the corresponding secondary antibodies for $20 \mathrm{~min}$, the bound complexes were visualized using a SuperPicture Polymer Detection kit (no. 87-8963; Invitrogen).

Angiogenesis vascularity evaluation. Angiogenesis vascularity was defined as the number of vessels per field counted in the area of the highest vascular density, termed as microvessel density (MVD). Endothelial cells were marked with an anti-CD34 antibody. The CD34 antigen was localized in the cytoplasm and cellular membrane of vascular endothelial cells. Single endothelial cells, endothelial cell clusters, and microvessels in the tumors, clearly separated from adjacent microvessels, were counted. Peritumoral vascularity and vascularity in areas of necrosis were not scored. A vascular lumen was not a requirement for a structure to be counted as a microvessel. Branching structures were counted as one, unless there was a break in the continuity of the vessel, in which case it was counted as two distinct vessels. Areas with a higher density of $\mathrm{CD} 4^{+}$cells and cell clusters relative to adjacent areas were classified as 'hot spots'. The slides were initially screened at low power to identify the areas with the highest number of microvessels or vascularity hot spots. Microvessels were counted in x400 magnification fields. MVD was defined as the number of manually counted vessel profiles per $\mathrm{mm}^{2}$, taken as the average from three hot-spot counts.

Collection of human CRC tissues. The study material was obtained from 129 patients with metastatic CRC whose tissue samples were available (mean age 62 years, range $26-82$ years) and who were treated from January 2007 to July 2016 at the First Affiliated Hospital of Soochow University. Patient characteristics are detailed in Table II. All human tissue samples were obtained and handled in accordance with an approved Institutional Review Board application (the Committee on Medical Ethics, the First Affiliated Hospital of Soochow University). Prognostic analyses were performed regarding overall survival (OS).

Statistical analysis. Each experiment was performed at least in triplicate. The results are expressed as the mean \pm standard deviation. Kaplan-Meier curves were constructed, and the statistical analysis was carried out using the log-rank test. OS was defined as the time from the diagnosed date to the time of death from any cause. Statistical analysis was performed using an unpaired Student's t-test. $\mathrm{P}<0.05$ was considered significant. 
A
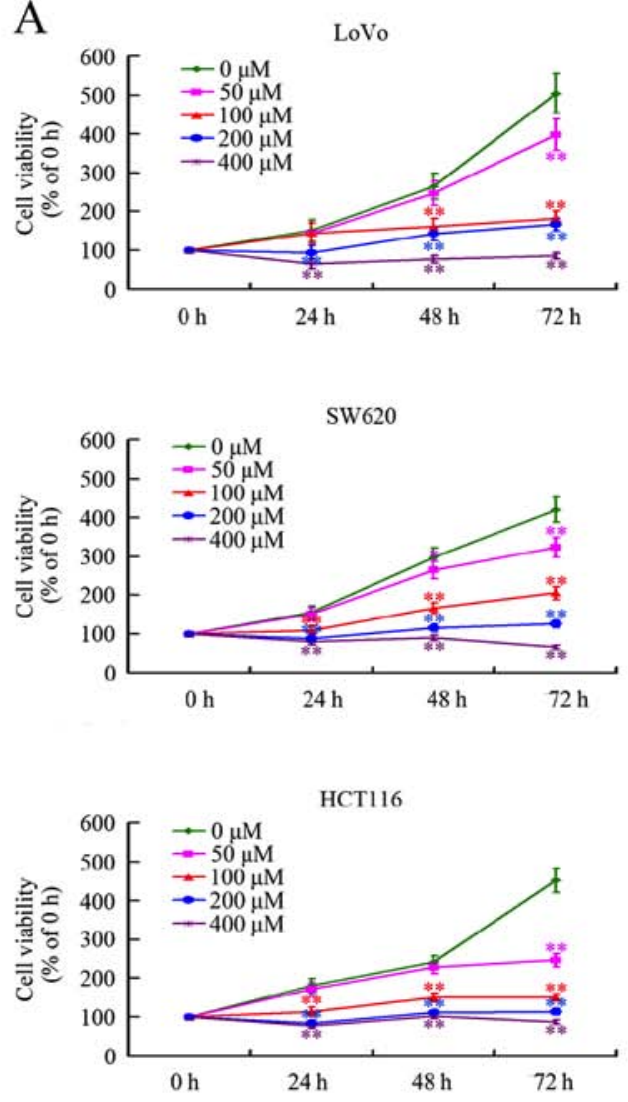

B
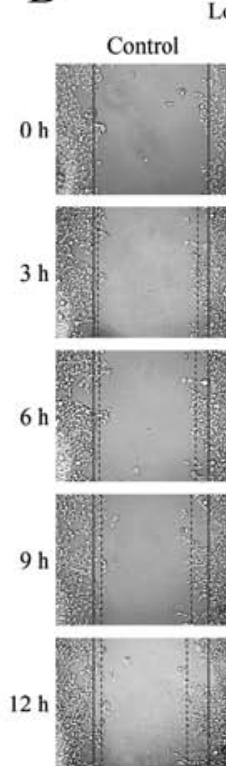

Vo
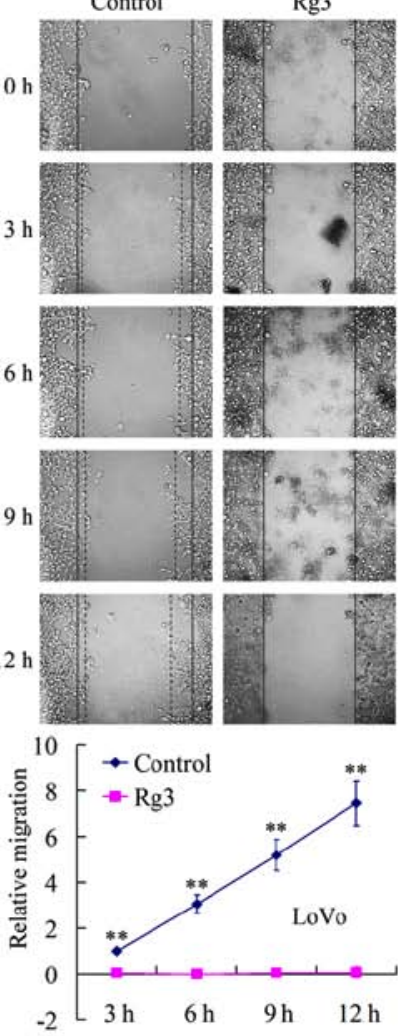
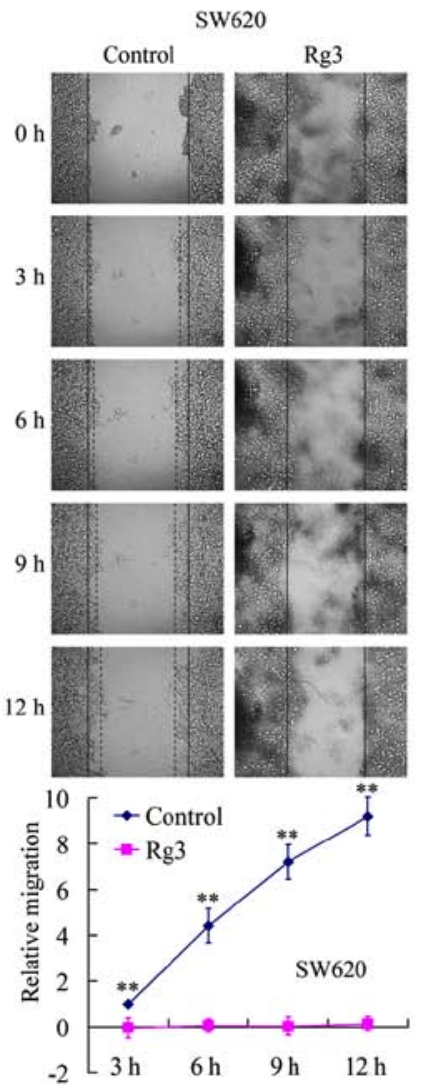

Figure 1. Rg3 represses the growth and migration of colorectal cancer (CRC) cells. (A) Exposure to various concentrations of Rg3 resulted in a dose- and timedependent growth inhibition on LoVo, SW620 and HCT116 CRC cells. (B) Treatment with $200 \mu \mathrm{M}$ Rg 3 resulted in time-dependent inhibition on the migration of LoVo and SW620 cells. ${ }^{*} \mathrm{P}<0.05$ and ${ }^{* *} \mathrm{P}<0.01$ indicate significant differences compared with the respective control groups.

\section{Results}

Rg3 suppresses the growth and migration of CRC cells in vitro. To investigate the effects of $\mathrm{Rg} 3$ on the biological behavior of CRC cells, MTT and wound healing assays were performed to evaluate cell growth and migration in vitro. The proliferation of LoVo, SW620, and HCT116 cells was all significantly inhibited by $\mathrm{Rg} 3$ in time- and dose-dependent manner (Fig. 1A). The wound healing assay verified that $\mathrm{Rg} 3$ inhibited migration of both LoVo and SW620 cells remarkably (Fig. 1B). These in vitro data confirmed that $\mathrm{Rg} 3$ had antitumor effects against CRC cells.

Rg3 impairs the stemness of CRC cells in vitro. It has been well accepted that there is a special subgroup of cancer cells in tumors, termed cancer stem cells (CSCs), which have been proven to preserve the abilities of extensive proliferation, selfrenewal, multi-lineage differentiation, drug-resistance, high metastasis and high tumorigenic potential (13-16).

CD24, CD44 and EpCAM are the well accepted colorectal CSC markers (13-16). To investigate whether Rg3 could affect the stemness of CRC cells, we examined the expressions of CD24, CD44 and EpCAM at both the mRNA and protein levels using real-time PCR and flow cytometry. As shown in Fig. 2A-D, the expression of these three markers was downregulated after treatment with $\mathrm{Rg} 3$. We then evaluated the positivity of CD24, CD44 and EpCAM on the surface of CRCs. The proportion of $\mathrm{CD} 24^{+} / \mathrm{CD} 44^{+} / \mathrm{EpCAM}^{+}$cells decreased significantly (Fig. 2E), suggesting the repressed stemness of CRCs after $\operatorname{Rg} 3$ treatment.

In addition, we further confirmed the stemness of the cells using a plate clone formation assay. LoVo and HCT116 were treated with $\operatorname{Rg} 3$ at different low doses and clone formation ability was then evaluated by calculating the visible clones. As shown in Fig. 2F and G, Rg3 treatment caused significant dose-dependent inhibition of the clone formation ability of CRC cells, which was consistent with the downregulation of CSC markers.

Rg3 represses growth and stemness of $C R C$ in vivo. We used an established orthotopic xenograft model to evaluate the antitumor effect of $\operatorname{Rg} 3$ in vivo. Treatment with $\mathrm{Rg} 3(25 \mathrm{mg} / \mathrm{kg})$ for 12 consecutive days significantly repressed the growth of the tumors (Fig. 3A and B). As shown in Fig. 3C and D, Rg3 downregulated the Ki-67 level, a major prognostic factor of tumors in general (17). Immunohistochemical assays further confirmed that $\mathrm{Rg} 3$ treatment downregulated the levels of stemness markers, CD24, CD44 and EpCAM, in the orthotopic xenografts (Fig. 3E-J), which was consistent with the in vitro data.

$R g 3$ represses angiogenesis of $C R C$. $\mathrm{Rg} 3$ is believed to inhibit angiogenesis in tumors; therefore, we investigated whether $\mathrm{Rg} 3$ could also affect vascularization of the CRC orthotopic 

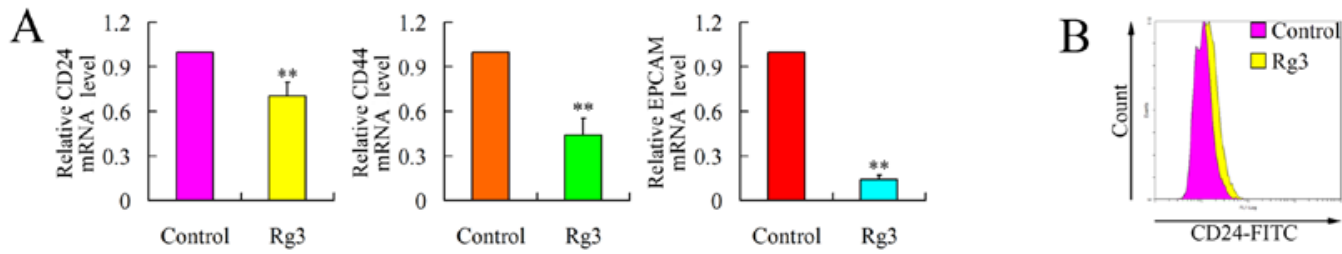

E
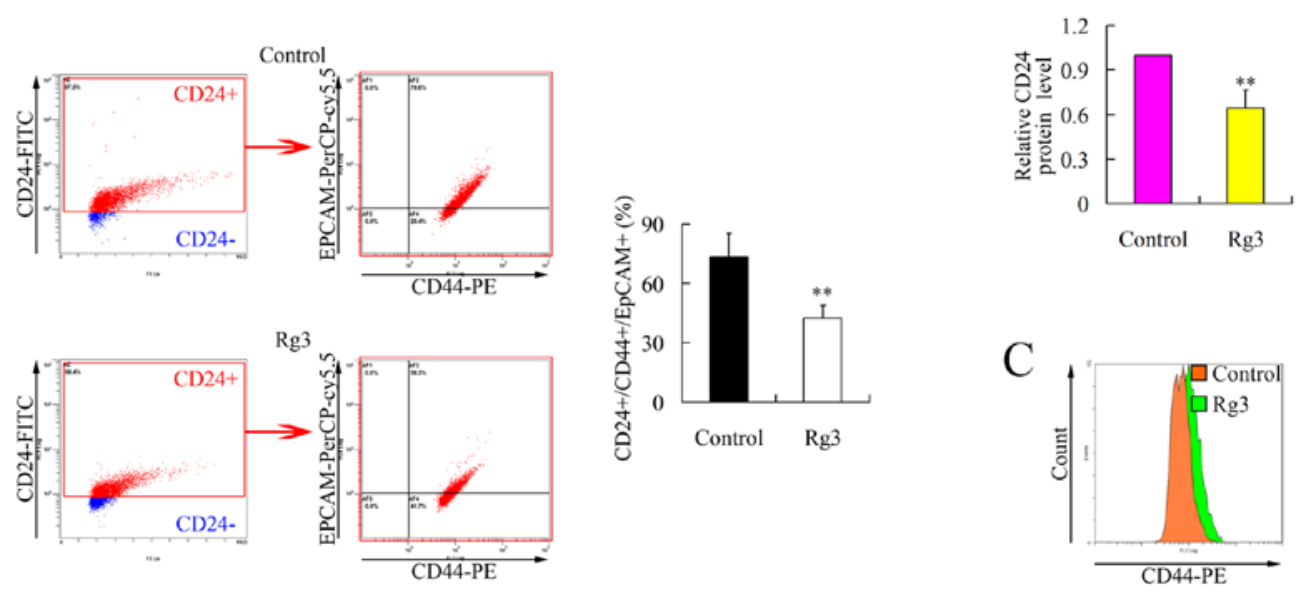

F
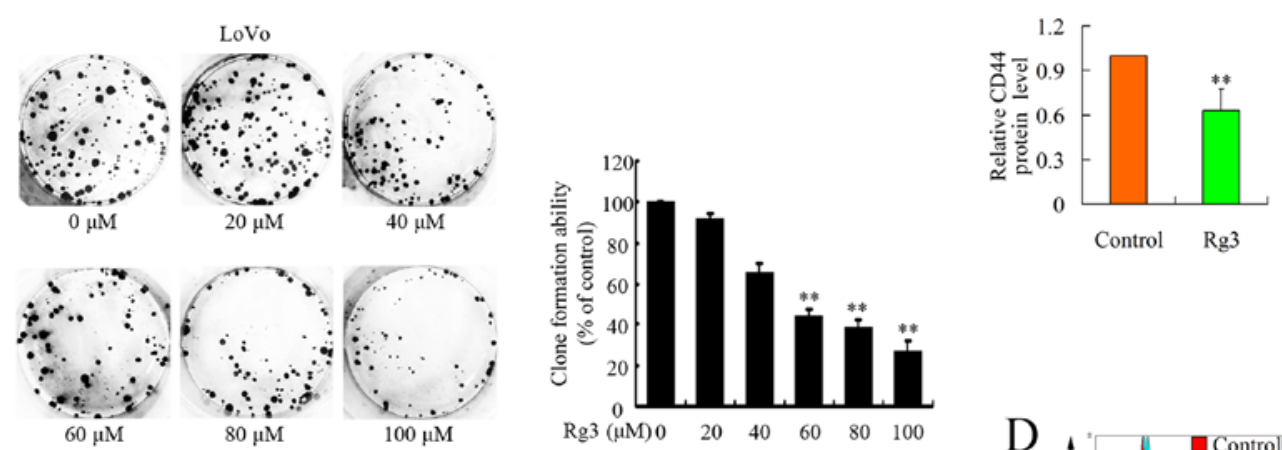

G
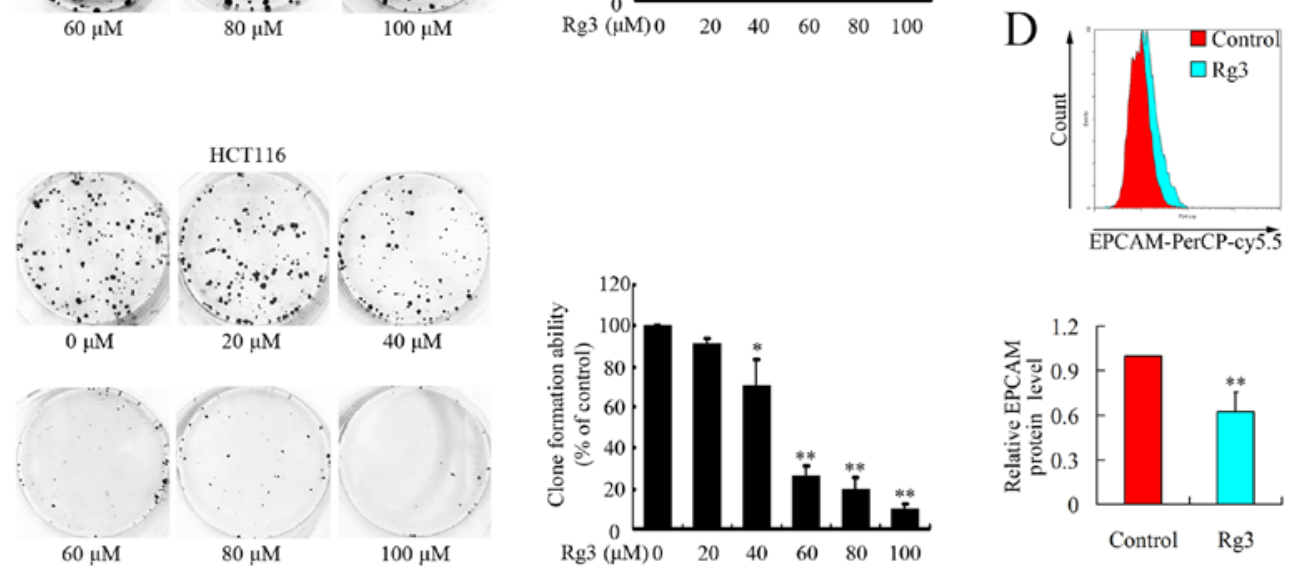

Figure 2. Rg3 represses the stemness of colorectal cancer (CRC) cells. (A) Rg3 repressed the expressions of CD24, CD44 and EpCAM at the mRNA level in LoVo cells. Cells were treated with $200 \mu \mathrm{M} \mathrm{Rg} 3$ and mRNA expressions were determined using real-time PCR. (B-D) Rg3 reducd the levels of CD24 (B), CD44 (C) and EpCAM (D) proteins in LoVo cells. Cells were treated with $200 \mu \mathrm{M} \mathrm{Rg} 3$ and protein levels were evaluated using flow cytometry. (E) Rg3 treatment $(200 \mu \mathrm{M})$ decreased the population of $\mathrm{CD} 24^{+} / \mathrm{CD} 44^{+} / \mathrm{EpCAM}^{+}$cells among LoVo cells. (F and $\left.\mathrm{G}\right) \mathrm{Rg} 3$ treatment inhibited the clone formation ability of LoVo (F) and HCT116 (G) cells in a dose-dependent manner. ${ }^{*} \mathrm{P}<0.05$ and ${ }^{* *} \mathrm{P}<0.01$ indicate significant differences compared with the respective control groups.

xenografts. Endothelial cells in the tissue were positively stained using an anti-CD34 antibody (Fig. 4A). The results showed that treatment with $\mathrm{Rg} 3$ repressed angiogenesis, according to the microvessel density (MVD) levels (Fig. 4B).

To investigate the mechanisms involved in $\mathrm{Rg} 3$-repressed angiogenesis, we analyzed the expression of 41 angiogenesisrelated genes (Table I) using real-time PCR. Among these genes, although $A N G, C C L 1$ and $C X C L 5$ were found to be upregulated (data not shown), 22 pro-angiogenic genes, including ANGPT1, ANGPT2, CCL13, COL18A, CSF3, CXCL1, EGF, FGF-2, IL1A, IL1B, IL8, KDR, MMP1, PGF, PIGF, PLAUR, TEK, THPO, TIMPI and TIMP2 were downregulated at the mRNA level after treatment with Rg3 (Fig. 4C). The expressions of the other 18 genes were unchanged after treatment 
A
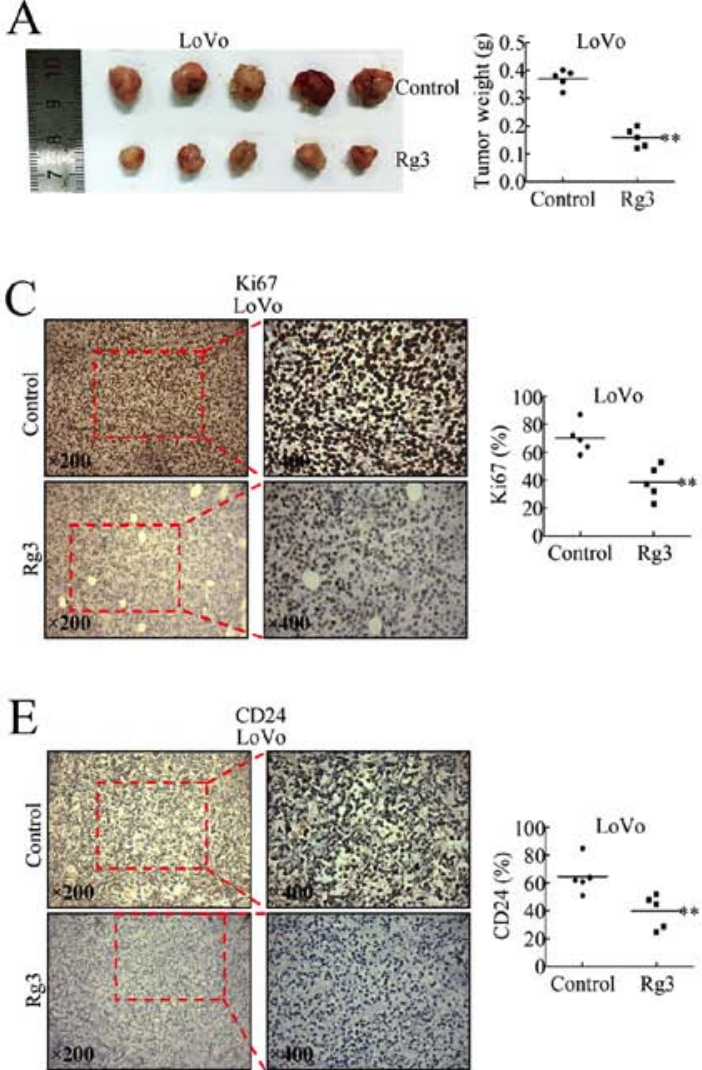

G
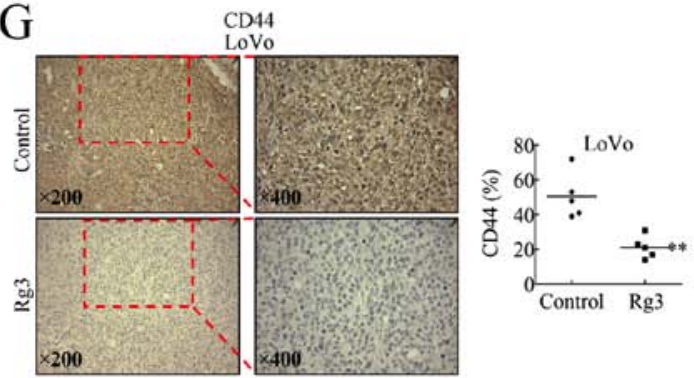

I
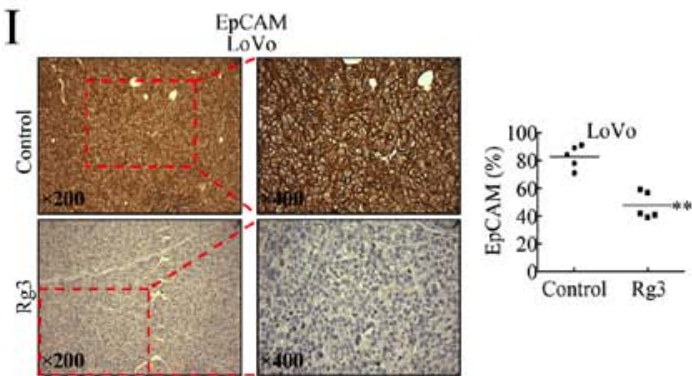

B
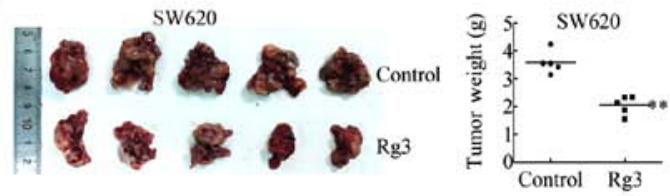

D
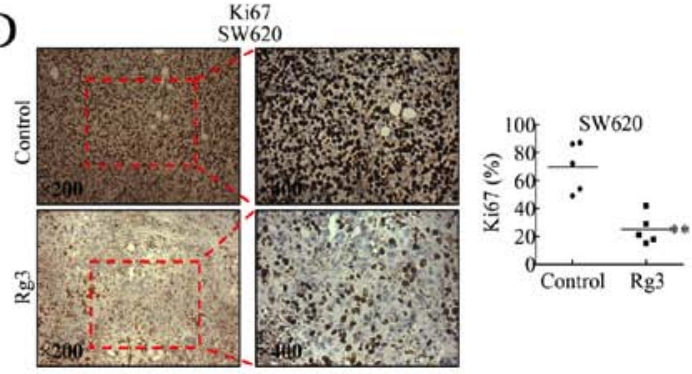

F
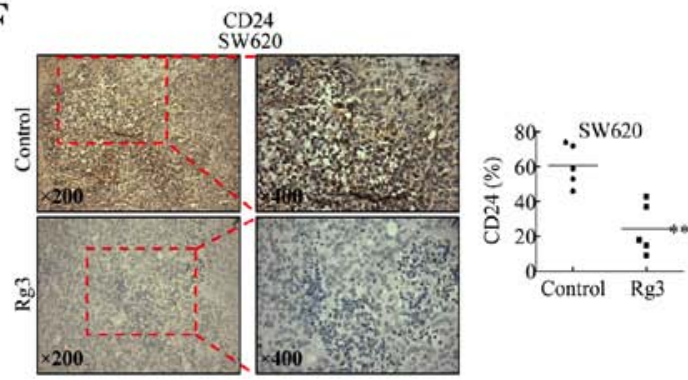

$\mathrm{H}$
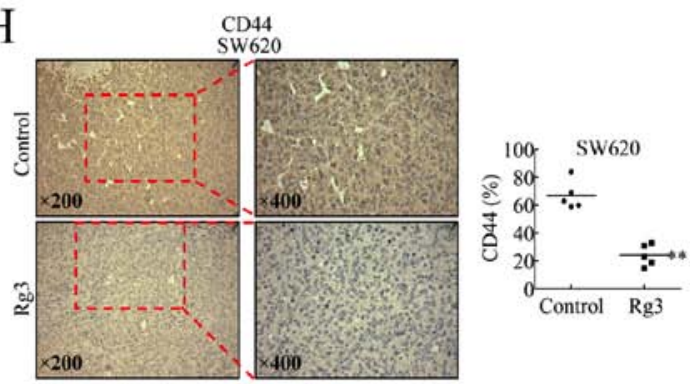

$\mathrm{J}$

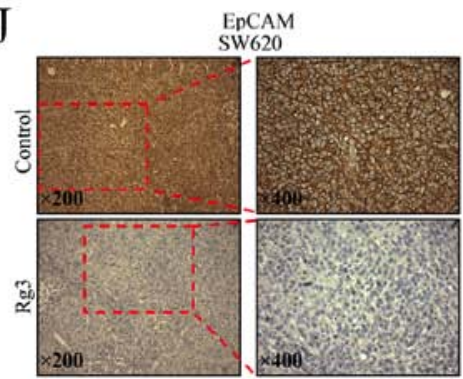

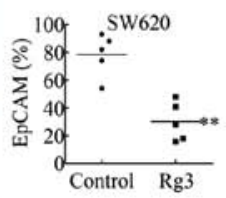

Figure 3. Rg3 represses growth and stemness of colorectal cancer (CRC) cells in vivo. (A) Images of resected LoVo and SW620 orthotopic xenografts. Mice bearing LoVo or SW620 orthotopic xenografts were randomly divided into two groups (five mice in each group): The Rg3 group, which received Rg3 by gastric perfusion daily $(25 \mathrm{mg} / \mathrm{kg}$ ) for 12 consecutive days, and the control group, which was treated with normal saline. (B) Tumor weights of resected LoVo and SW620 orthotopic xenografts. (C-J) Immunohistochemical examination of Ki-67 (C and D), CD24 (E and F), CD44 (G and H) and EpCAM (I and J) levels in LoVo and SW620 orthotopic xenografts. ${ }^{*} \mathrm{P}<0.05$ and ${ }^{* *} \mathrm{P}<0.01$ indicate significant differences compared with the respective control groups.

with Rg3 (data not shown). Therefore, it is possible that the anti-angiogenic effect of $\operatorname{Rg} 3$ is executed by downregulating the expression of certain angiogenesis-related genes.

Rg3 strengthens the cytotoxicity of 5-Fu and oxaliplatin in vivo. $\mathrm{Rg} 3$ impaired the stemness of CRC cells and repressed angiogenesis; therefore, we next investigated whether $\operatorname{Rg} 3$ could improve the cytotoxicity of 5-Fu and oxaliplatin, two widely used first line pharmacotherapeutics in clinical treatments.

Separately, $\operatorname{Rg} 3,5-\mathrm{Fu}$ and oxaliplatin could repress growth of the xenografts (Fig. 5). However, the combinations of Rg3 
A

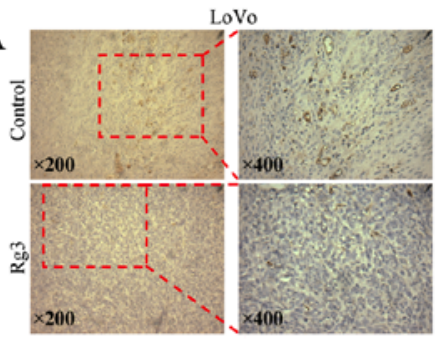

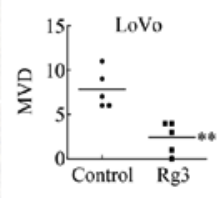
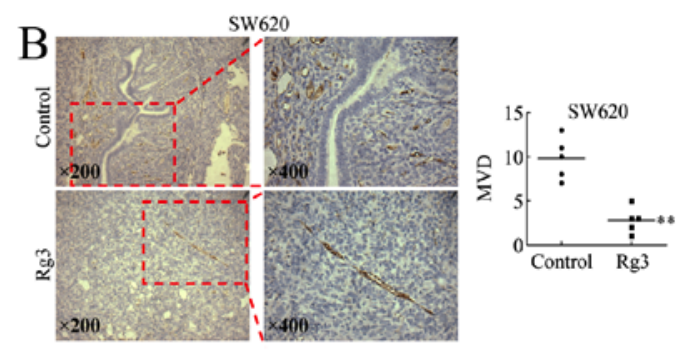

$\mathrm{C}$

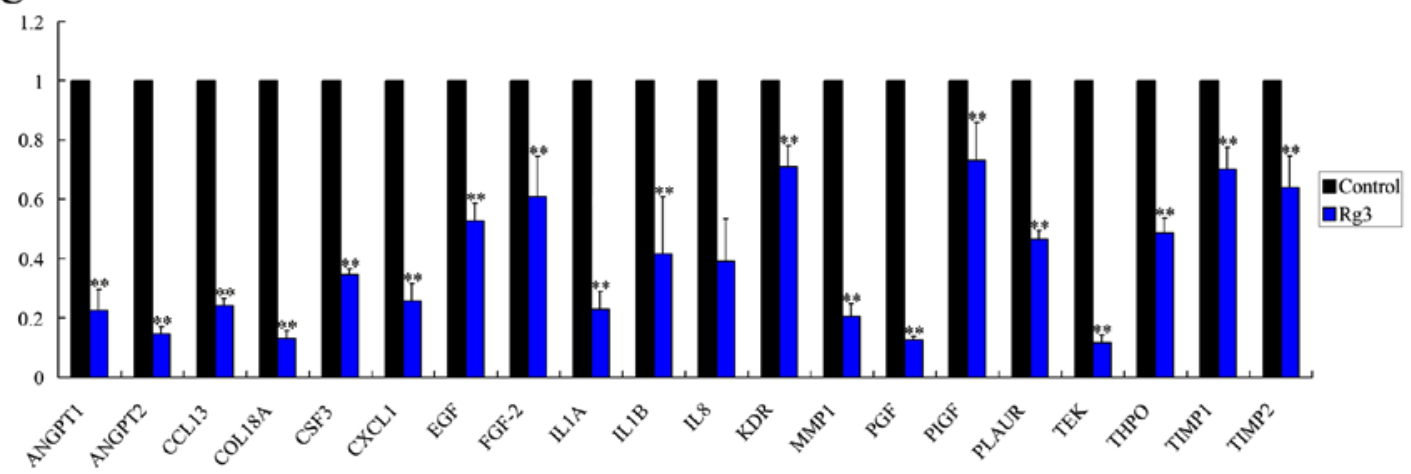

Figure 4. Rg3 represses angiogenesis of colorectal cancer (CRC). (A) Immunohistochemical examination of LoVo and SW620 orthotopic xenografts using an anti-CD34 antibody. (B) Rg3 treatment decreased the microvessel density (MVD) levels in both LoVo and SW620 orthotopic xenografts. (C) Real-time PCR showing that Rg3 downregulated the expression of angiogenesis-related genes in LoVo cells. ${ }^{*} \mathrm{P}<0.05$ and ${ }^{* *} \mathrm{P}<0.01$ indicate significant differences compared with the respective control groups.
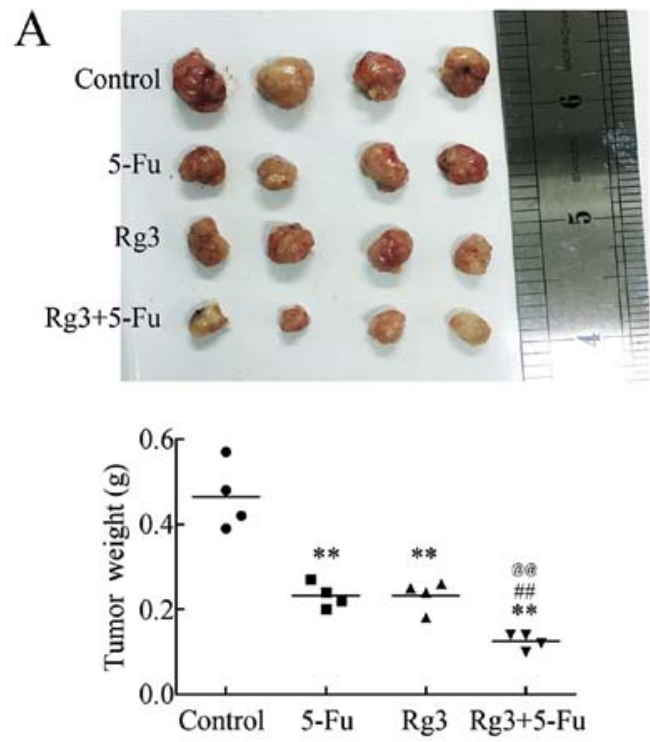
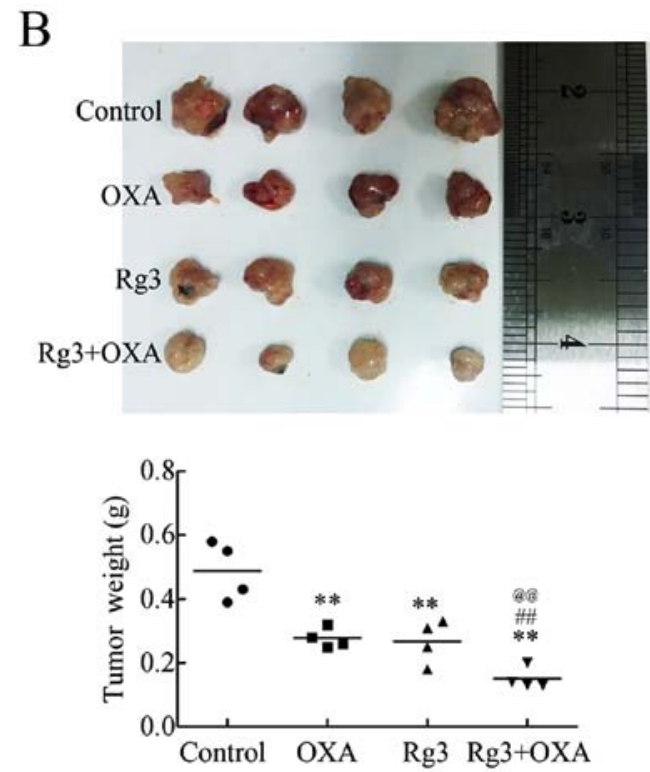

Figure 5. Rg3 strengthens the cytotoxicity of fluorouracil (5-Fu) and oxaliplatin (OXA). (A) Iamges and weights of resected LoVo orthotopic xenografts treated by Rg3 and/or 5-Fu. (B) Photographs and weights of resected LoVo orthotopic xenograft s treated by Rg3 and/or OXA. ${ }^{* *} \mathrm{P}<0.01$ indicates significant differences compared with the respective control groups. ${ }^{\# \#} \mathrm{P}<0.01$ indicates significant differences compared with the respective chemotherapy groups. ${ }^{\circledR}$ $\mathrm{P}<0.01$ indicates significant differences from the respective $\mathrm{Rg} 3$ groups.

and 5-Fu, or $\mathrm{Rg} 3$ and oxaliplatin, decreased the volumes of the tumors to much more significant levels. Furthermore, the weights of the tumors were also consistent with the images (Fig. 5), suggesting that $\operatorname{Rg} 3$ could act as a supplement for chemotherapy regimens containing 5-Fu or oxaliplatin.

Rg3 downregulates the levels of $\mathrm{B} 7-\mathrm{H} 1$ and $\mathrm{B} 7-\mathrm{H} 3$, predictors of adverse clinical outcomes in CRC. B7-H1 and B7-H3 belong to B7 family, and play important roles in tumor immune responses by integrating $\mathrm{T}$ cell receptor signaling to regulate $\mathrm{T}$ cell function. To confirm the relationship between outcomes of CRC patients and the levels of B7-H1 and B7-H3, we collected tissue samples from 129 patients with metastatic CRC, and assessed the levels of B7-H1 and B7-H3 using immunohistochemistry. The representative microscope images of immunohistochemical staining of B7-H1 and B7-H3 

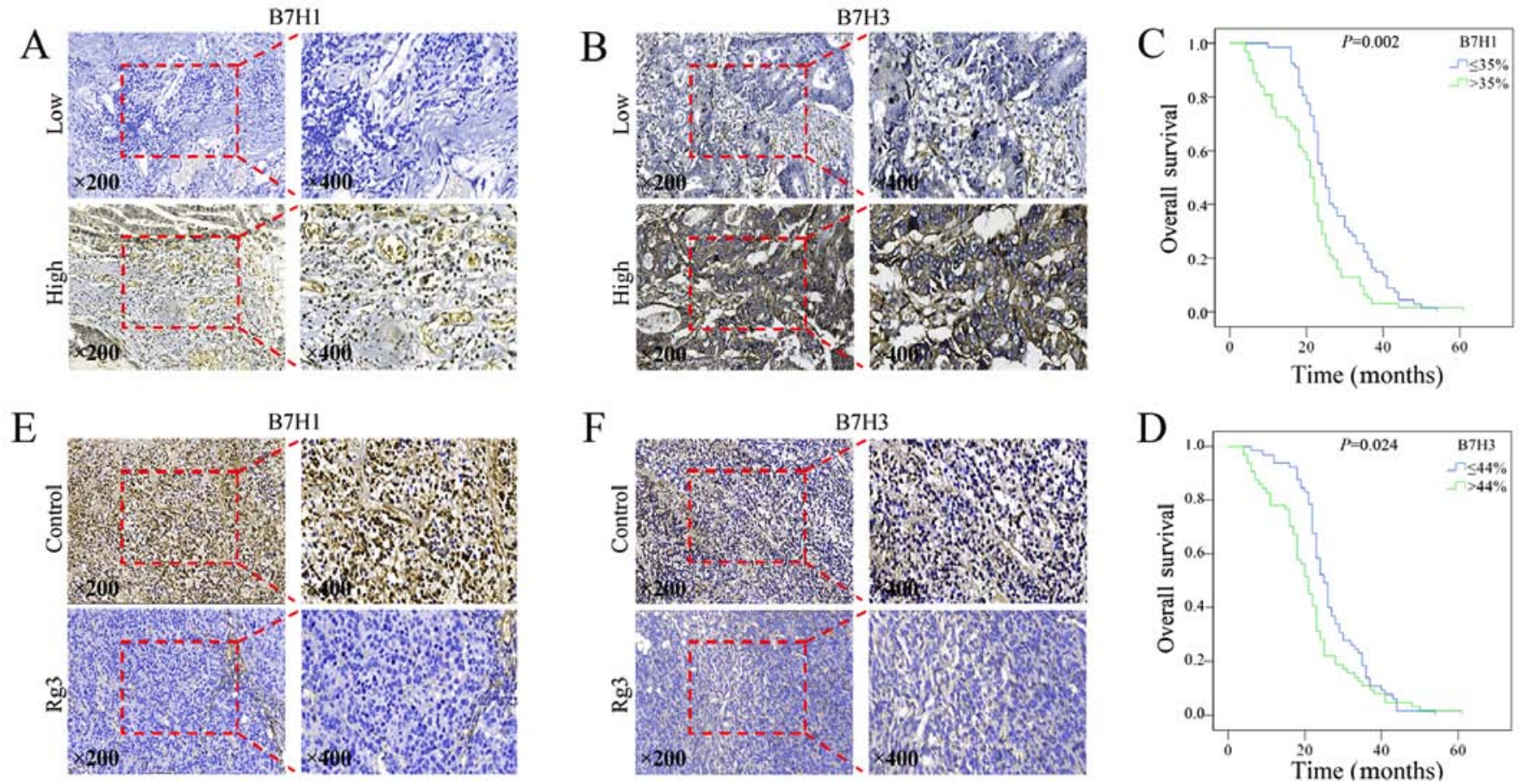

Figure 6. Rg3 downregulates the levels of B7-H1 and B7-H3 in colorectal cancer (CRC). (A and B) Immunohistochemical examinations of B7H1 (A) and B7H3 (B) levels in human CRC tissue samples. (C and D) Kaplan-Meier curves for CRC overall survival according to tumor B7-H1 (C) and B7-H3 (D) expression status (low vs. high, $\mathrm{P}<0.01$ ). (E and F) Immunohistochemical examination of B7H1 (E) and B7H3 (F) levels in LoVo orthotopic xenografts after Rg3 treatment.

are shown in Fig. 6A and B, respectively. High levels of B7-H1 and B7-H3 were significantly associated with liver metastasis (Table II) and reduced overall survival (Fig. 6C and D).

The levels of B7-H1 and B7-H3 were then evaluated in Rg3-treated CRC orthotopic xenografts. As shown in Fig. 6E and $\mathrm{F}, \mathrm{Rg} 3$ significantly decreased the levels of both B7-H1 and $\mathrm{B} 7-\mathrm{H} 3$, suggesting that $\mathrm{Rg} 3$ might also promote antitumor immunity.

\section{Discussion}

Ginsenoside $\operatorname{Rg} 3$ exhibits antitumor activity in various tumors $(9,10)$. In the present study, $\operatorname{Rg} 3$ exerted an inhibitory effect on the proliferation and migration of CRC cells in a dose- and time-dependent manner. In addition, $\operatorname{Rg} 3$ inhibited the growth of CRC orthotopic xenografts in vivo. Immunohistochemistry showed that Ki-67, a well-known proliferation index, was dramatically downregulated in Rg3-treated subjects.

CSCs, which have aberrant differentiation programs that generate progenitor cancer cells, play a crucial role in the formation of many solid tumors, including CRC. Deregulation of the pathways of self-renewal and differentiation in CSCs result in unlimited self-renewal and a subsequent excess of CSCs, which are the source of tumor formation $(13,18)$. Recent studies have demonstrated that CSCs are drug-resistant and exhibited high propensity of invasiveness and metastasis (13-16). The presence of CSCs is also related to immune escape (19). These features of CSCs result in cancer recurrence after eliminating most of the cancer cells by conventional therapies. Therefore, it is of paramount importance to develop therapies targeting CSCs. Markers, including CD24, CD44,
EpCAM and CD133, have been utilized to identify CSCs in CRC (14-16). Combined analysis of these markers has been used to identify CSCs. In the present study, we used the panel of CD24, CD44 and EpCAM to analyze the stemness of CRC, and demonstrated that $\mathrm{Rg} 3$ decreased the population of $\mathrm{CD} 24^{+} /$ $\mathrm{CD}_{4} 4^{+} / \mathrm{EpCAM}^{+} \mathrm{CRCs}$ cells, the presumed CRCs. In addition, we detected decreased $\mathrm{CD} 24^{+} / \mathrm{CD} 44^{+} / \mathrm{EpCAM}^{+}$proportions in orthotopic xenografts tissue samples using immunohistochemistry. Plate clone formation assays further confirmed the repressed clone formation ability by $\operatorname{Rg} 3$ treatment. Therefore, we speculated that the anticancer effect of $\mathrm{Rg} 3$ might also involve eliminating colorectal CSCs.

A previous study proved that $\mathrm{Rg} 3$ plays a unique role in impairing angiogenesis in tumors by inhibiting the growth of vein endothelial cells (5). To investigate whether anti-angiogenesis is involved as a mechanism of the antitumor effect of $\mathrm{Rg} 3$, we evaluated the MVD, a well recognized indicator for vascularization. As expected, a lower MVD was detected in Rg3-treated subjects, suggesting inhibition of neoangiogenesis might also be involved in the growth-inhibition effect of $\operatorname{Rg} 3$ against CRC.

Using real-time PCR, we further analyzed the expression of angiogenesis-related genes in $\mathrm{Rg} 3$-treated CRC cells, and found 22 pro-angiogenic genes ANGPT1, ANGPT2, CCL13, COL18A, CSF3, CXCL1, EGF, FGF-2,IL1A, IL1B, IL8, KDR, $M M P 1, P G F$, PIGF, PLAUR, TEK, THPO, TIMP1 and TIMP2 were significantly downregulated. ANGPT1 (angiopoietin 1) and ANGPT2 (angiopoietin 2) belong to the angiopoietin family. Members of this family play important roles in vascular development, and are correlated with tumor stage, disease progression, or metastasis (20). CCL13 (C-C motif chemokine ligand 13) and CXCL1 (C-X-C motif chemokine 
ligand 1) are chemokines that play important roles in the initial step of inflammation and angiogenesis $(21,22)$. COL18A (collagen type XVIII alpha 1 chain) is reported to participate in regulating cell growth and apoptosis, inflammation, angiogenesis and tissue turnover (23). CSF3 (colony stimulating factor 3 ) is involved in various types of angiogenesis and skin wound healing by inducing VEGF release from neutrophils, thus promoting neovascularization (24). EGF (epidermal growth factor) is a member of the epidermal growth factor superfamily, which plays an important role in the growth, proliferation, and differentiation of numerous cell types, and has been demonstrated to have a critical role in tumor angiogenesis by enhancing the expression of VEGF (25). MMP1 (matrix metallopeptidase 1) has been identified as an important participant in tumor invasion, metastasis, and angiogenesis (26). IL1A (interleukin 1 alpha) and IL1B (interleukin 1 beta) are members of the interleukin 1 cytokine family, which are involved in various immune responses, inflammatory processes, and hematopoiesis and also play crucial roles in the tumorigenesis of colorectal cancer (27). IL8 (interleukin 8), PLAUR (plasminogen activator, urokinase receptor), and THPO (thrombopoietin) participate in angiogenesis in a WNT/ $\beta$-catenin pathway-dependent manner (17). PGF (placental growth factor) encodes a growth factor found in the placenta that is homologous to VEGF (vascular endothelial growth factor). Knockdown of PGF has been reported to exert antitumor effect through PI3K/AKT and p38 MAPK signal transduction (28). TEK (vascular endothelial cell specific receptor tyrosine kinase) has been reported to play a crucial role in embryonic vascular development (29). Therefore, it is possible that $\mathrm{Rg} 3$ represses angiogenesis in CRC through mechanisms involving the downregulation of multiple angiogenesis-related genes.

Much effort has been made towards discovering new antiangiogenic agents. Bevacizumab is a partially humanized monoclonal antibody that binds to VEGF (30). It has been widely accepted that bevacizumab can reasonably be added to either FOLFIRI or FOLFOX chemotherapy regimens for patients undergoing first-line treatment of metastatic CRC (7). Studies have proven that bevacizumab can improve the median overall survival (OS) of patients with metastatic CRC. In research performed in the USA, 820 patients with metastatic CRC were randomly assigned to chemotherapy with bevacizumab or chemotherapy without bevacizumab. Patients who received bevacizumab experienced an improved OS (11.2 months) compared with the patients who did not receive bevacizumab (9.8 months). Median progression-free survival was 5.7 months for patients who received bevacizumab plus chemotherapy and 4.1 months for those who received chemotherapy without bevacizumab (31). Based on these data, we concluded that anti-angiogenic therapy is effective in the treatment of CRC, especially for patients with relapse and metastasis $(2,3)$.

$\mathrm{Rg} 3$ is able to eliminate chemotherapy-resistant CSCs and preserve its anti-angiogenic ability; therefore, we speculated that Rg3 could be an effective supplement to chemotherapy regimens. 5-Fu is a pyrimidine class antagonist that interferes with the growth of cancer cells, and is currently a cornerstone in the therapeutic regimens of metastatic or advanced-stage CRC. Oxaliplatin, as a third-generation platinum drug, is commonly used in the adjuvant and palliative treatments of CRC. Therefore, we investigated whether Rg3 could be applied to treatments with 5-Fu and oxaliplatin. Using mouse orthotopic xenografts models, we proved that the combination of $\mathrm{Rg} 3$ and pharmacotherapies of 5-Fu or oxaliplatin presented stronger cytotoxicity against CRC than either chemotherapy alone. Therefore, $\operatorname{Rg} 3$ shows promise for future clinical applications.

Immune escape plays an important role in the development of tumors. B7-H1 is also known as programmed death ligand-1 (PDL-1) or CD274 and B7-H3 is also known as CD206. Both belong to the $\mathrm{B} 7$ family, and play important roles in tumor immune responses by integrating $\mathrm{T}$ cell receptor signaling to regulate $\mathrm{T}$ cell function. $\mathrm{B} 7-\mathrm{H} 1$ and $\mathrm{B} 7-\mathrm{H} 3$ are recognized as predictive and prognostic factors in various cancers. The interaction between B7-H1 and PD-1 inhibits the activation of tumor antigen-specific $\mathrm{T}$ cells, and induces immune tolerance of $\mathrm{T}$ cells to tumor cells, by which the tumor cells evade immune surveillance $(32,33)$. Higher expression levels of B7-H1 are associated with more advanced diseases, increased risks of recurrence and/or shorter survival time (34-36). B7-H3 is induced in activated dendritic cells, monocytes, and $\mathrm{T}$ cells with an immunoglobulin-like structure, and is highly expressed in numerous types of cancers (37-41). Aberrant expression of B7-H3 has been reported to be associated with poor prognosis in patients with colorectal and breast cancer $(42,43)$. B7-H3 can promote tumor progression and cancer cell metastasis, as well as correlating with malignancy grades and the outcomes of patients with tumors, including CRC (44-46).

In the analysis of CRC tissue samples, we confirmed that high expression of B7-H1 and B7-H3 was significantly associated with worse outcomes of patients with CRC, which was consistent with previous studies. Moreover, by examining CRC orthotopic xenografts, we found that $\mathrm{Rg} 3$ could decrease the level of B7-H1 and B7-H3, suggesting that Rg3 might be able to promote antitumor immunity. However, considering that the nude mouse is a model of deficient T-cell function, we should be wary of making this conclusion based on the present data. Further investigations are required to confirm the anti-immune escape effect of $\mathrm{Rg} 3$.

Taken together, the results of this study showed that $\operatorname{Rg} 3$ not only inhibited the growth and migration of CRC, but also strengthened the cytotoxicity of 5-Fu and oxaliplatin in vivo. This special antitumor effect might partly depend on attenuating the stemness of CRC cells and remodeling the tumor microenvironment by repressing angiogenesis. In view of this, $\mathrm{Rg} 3$ has the potential for clinical application in CRC treatment in the future, and may represent a novel approach to treat this aggressive disease.

\section{Acknowledgements}

The present study was supported by the National Natural Science Foundation of China (grant nos. 81472296, 81602091, 81402176, 81402093, 81272542 and 81200369), the Six Major Talent Peak Project of Jiangsu Province (grant no. 2015-WSN022), the Project of Invigorating Health Care through Science, Technology and Education, Jiangsu Provincial Medical Youth Talent (grant no. QNRC2016709), the Project of Jiangsu Provincial Commission of Health and Family Planning 
(grant no. H201518), the Science and Education for Health Foundation of Suzhou for Youth (grant no. kjxw2015003), and the Science and Technology Project Foundation of Suzhou (grant nos. SYS201464 and SYS201504).

\section{References}

1. Crotti S, Piccoli M, Rizzolio F, Giordano A, Nitti D and Agostini M: Extracellular matrix and colorectal cancer: How surrounding microenvironment affects cancer cell behavior? J Cell Physiol 232: 967-975, 2017.

2. Colon Cancer Treatment: (PDQ(R)): Health Professional Version In: PDQ Cancer Information Summaries. Bethesda (MD), 2002.

3. Siegel RL, Miller KD and Jemal A: Cancer Statistics, 2017. CA Cancer J Clin 67: 7-30, 2017.

4. Pattison AM, Merlino DJ, Blomain ES and Waldman SA Guanylyl cyclase $\mathrm{C}$ signaling axis and colon cancer prevention. World J Gastroenterol 22: 8070-8077, 2016.

5. Yue PY, Wong DY, Wu PK, Leung PY, Mak NK, Yeung HW, Liu L, Cai Z, Jiang ZH, Fan TP, et al: The angiosuppressive effects of 20(R)- ginsenoside Rg3. Biochem Pharmacol 72 : 437-445, 2006.

6. Fan F, Schimming A, Jaeger D and Podar K: Targeting the tumor microenvironment: Focus on angiogenesis. J Oncol 2012: $281261,2012$.

7. Ferrara N, Hillan KJ and Novotny W: Bevacizumab (Avastin), a humanized anti-VEGF monoclonal antibody for cancer therapy. Biochem Biophys Res Commun 333: 328-335, 2005.

8. Chen QJ, Zhang MZ and Wang LX: Gensenoside Rg3 inhibits hypoxia-induced VEGF expression in human cancer cells. Cell Physiol Biochem 26: 849-858, 2010.

9. Junmin S, Hongxiang L, Zhen L, Chao Y and Chaojie W Ginsenoside Rg3 inhibits colon cancer cell migration by suppressing nuclear factor kappa B activity. J Tradit Chin Med 35: 440-444, 2015.

10. Yuan HD, Quan HY, Zhang Y, Kim SH and Chung SH: 20(S)-Ginsenoside Rg3-induced apoptosis in HT-29 colon cancer cells is associated with AMPK signaling pathway. Mol Med Rep 3: 825-831, 2010.

11. Li W, Xie L, Chen Z, Zhu Y, Sun Y, Miao Y, Xu Z and Han X: Cantharidin, a potent and selective PP2A inhibitor, induces an oxidative stress-independent growth inhibition of pancreatic cancer cells through $\mathrm{G} 2 / \mathrm{M}$ cell-cycle arrest and apoptosis. Cancer Sci 101: 1226-1233, 2010.

12. Wang J, Chen C, Wang S, Zhang Y, Yin P, Gao Z, Xu J, Feng D, Zuo Q, Zhao R, et al: Bufalin inhibits HCT116 colon cancer cells and its orthotopic xenograft tumor in mice model through genes related to apoptotic and PTEN/AKT pathways. Gastroenterol Res Pract 2015: 457193, 2015

13. Wahab SMR, Islam F, Gopalan V and Lam AK: The identifications and clinical implications of cancer stem cells in colorectal cancer. Clin Colorectal Cancer 16: 93-102, 2017.

14. Cherciu I, Bărbălan A, Pirici D, Mărgăritescu C and Săftoiu A: Stem cells, colorectal cancer and cancer stem cell markers correlations. Curr Health Sci J 40: 153-161, 2014.

15. Vaiopoulos AG, Kostakis ID, Koutsilieris $M$ and Papavassiliou AG: Colorectal cancer stem cells. Stem Cells 30: 363-371, 2012.

16. Ren F, Sheng WQ and Du X: CD133: A cancer stem cells marker, is used in colorectal cancers. World J Gastroenterol 19: 2603-2611, 2013

17. Liu L, Zhi Q, Shen M, Gong FR, Zhou BP, Lian L, Shen B, Chen K, Duan W, Wu MY, et al: FH535, a $\beta$-catenin pathway inhibitor, represses pancreatic cancer xenograft growth and angiogenesis. Oncotarget 7: 47145-47162, 2016.

18. Wang WJ, Wu MY, Shen M, Zhi Q, Liu ZY, Gong FR, Tao M and Li W: Cantharidin and norcantharidin impair stemness of pancreatic cancer cells by repressing the $\beta$-catenin pathway and strengthen the cytotoxicity of gemcitabine and erlotinib. Int $\mathbf{J}$ Oncol 47: 1912-1922, 2015.

19. Reim F, Dombrowski Y, Ritter C, Buttmann M, Häusler S, Ossadnik M, Krockenberger M, Beier D, Beier CP, Dietl J, et al: Immunoselection of breast and ovarian cancer cells with trastuzumab and natural killer cells: Selective escape of CD44high/ CD24low/HER2low breast cancer stem cells. Cancer Res 69: 8058-8066, 2009.
20. Güveli ME, Duranyildiz D, Karadeniz A, Bilgin E, Serilmez M, Soydinc HO and Yasasever V: Circulating serum levels of angiopoietin-1 and angiopoietin-2 in nasopharynx and larynx carcinoma patients. Tumour Biol 37: 8979-8983, 2016.

21. Yamaguchi A, Nozawa K, Fujishiro M, Kawasaki M, Suzuki F, Takamori K, Ogawa H, Takasaki Y and Sekigawa I: CC motif chemokine ligand 13 is associated with rheumatoid arthritis pathogenesis. Mod Rheumatol 23: 856-863, 2013.

22. Lai TH, Wu PH and Wu WB: Involvement of NADPH oxidase and NF- $\kappa \mathrm{B}$ activation in CXCL1 induction by vascular endothelial growth factor in human endometrial epithelial cells of patients with adenomyosis. J Reprod Immunol 118: 61-69, 2016.

23. Luo X, Pan Q, Liu L and Chegini N: Genomic and proteomic profiling II: Comparative assessment of gene expression profiles in leiomyomas, keloids, and surgically-induced scars. Reprod Biol Endocrinol 5: 35, 2007.

24. Kameyama H, Udagawa O, Hoshi T, Toukairin Y, Arai T and Nogami M: The mRNA expressions and immunohistochemistry of factors involved in angiogenesis and lymphangiogenesis in the early stage of rat skin incision wounds. Leg Med (Tokyo) 17: 255-260, 2015.

25. Hung MS, Chen IC, Lin PY, Lung JH, Li YC, Lin YC, Yang CT and Tsai YH: Epidermal growth factor receptor mutation enhances expression of vascular endothelial growth factor in lung cancer. Oncol Lett 12: 4598-4604, 2016.

26. Zhang Z, Wang L, Du J, Li Y, Yang H, Li C, Li H and Hu H: Lipid raft localization of epidermal growth factor receptor alters matrix metalloproteinase-1 expression in SiHa cells via the MAPK/ERK signaling pathway. Oncol Lett 12: 4991-4998, 2016.

27. Yan H, Sun R, Pan X, Li Z, Guo X and Gao L: Lack of association between an insertion/deletion polymorphism in IL1A and risk of colorectal cancer. Genet Mol Res 14: 8490-8495, 2015.

28. Akrami H, Mahmoodi F, Havasi S and Sharifi A: PlGF knockdown inhibited tumor survival and migration in gastric cancer cell via PI3K/Akt and p38MAPK pathways. Cell Biochem Funct 34: 173-180, 2016.

29. Dopheide JF, Geissler P, Rubrech J, Trumpp A, Zeller GC, Bock K, Dorweiler B, Dünschede F, Münzel T, Radsak MP, et al: Inflammation is associated with a reduced number of proangiogenic Tie-2 monocytes and endothelial progenitor cells in patients with critical limb ischemia. Angiogenesis 19: 67-78, 2016.

30. Koukourakis GV and Sotiropoulou-Lontou A: Targeted therapy with bevacizumab (Avastin) for metastatic colorectal cancer. Clin Transl Oncol 13: 710-714, 2011.

31. Bennouna J, Sastre J, Arnold D, Österlund P, Greil R, Van Cutsem E, von Moos R, Viéitez JM, Bouché O, Borg C, et al; ML18147 Study Investigators: Continuation of bevacizumab after first progression in metastatic colorectal cancer (ML18147): A randomised phase 3 trial. Lancet Oncol 14: 29-37, 2013.

32. Chen Z, Pang N, Du R, Zhu Y, Fan L, Cai D, Ding Y and Ding J: Elevated expression of programmed death-1 and programmed death Ligand-1 negatively regulates immune response against cervical cancer cells. Mediators Inflamm 2016: 6891482, 2016.

33. Bryan LJ and Gordon LI: Releasing the brake on the immune system: The PD-1 strategy for hematologic malignancies. Oncology (Williston Park) 29: 431-439, 2015.

34. Baptista MZ, Sarian LO, Derchain SF, Pinto GA and Vassallo J: Prognostic significance of PD-L1 and PD-L2 in breast cancer. Hum Pathol 47: 78-84, 2016.

35. Reiss KA, Forde PM and Brahmer JR: Harnessing the power of the immune system via blockade of PD-1 and PD-L1: A promising new anticancer strategy. Immunotherapy 6: 459-475, 2014.

36. Ghebeh H, Mohammed S, Al-Omair A, Qattan A, Lehe C, Al-Qudaihi G, Elkum N, Alshabanah M, Bin Amer S, Tulbah A, et al: The B7-H1 (PD-L1) T lymphocyte-inhibitory molecule is expressed in breast cancer patients with infiltrating ductal carcinoma: Correlation with important high-risk prognostic factors. Neoplasia 8: 190-198, 2006.

37. Sun M, Richards S, Prasad DV, Mai XM, Rudensky A and Dong C: Characterization of mouse and human B7-H3 genes. J Immunol 168: 6294-6297, 2002.

38. Chapoval AI, Ni J, Lau JS, Wilcox RA, Flies DB, Liu D, Dong H, Sica GL, Zhu G, Tamada K, et al: B7-H3: A costimulatory molecule for $\mathrm{T}$ cell activation and IFN-gamma production. Nat Immunol 2: 269-274, 2001. 
39. Steinberger P, Majdic O, Derdak SV, Pfistershammer K Kirchberger S, Klauser C, Zlabinger G, Pickl WF, Stöckl J and Knapp W: Molecular characterization of human 4Ig-B7-H3, a member of the B7 family with four Ig-like domains. J Immunol 172: 2352-2359, 2004

40. Xu H, Cheung IY, Guo HF and Cheung NK: MicroRNA miR-29 modulates expression of immunoinhibitory molecule B7-H3 Potential implications for immune based therapy of human solid tumors. Cancer Res 69: 6275-6281, 2009.

41. Wang F, Wang G, Liu T, Yu G, Zhang G and Luan X: B7-H3 was highly expressed in human primary hepatocellular carcinoma and promoted tumor progression. Cancer Invest 32: 262-271, 2014.

42. Ingebrigtsen VA, Boye K, Nesland JM, Nesbakken A Flatmark K and Fodstad Ø: B7-H3 expression in colorectal cancer: Associations with clinicopathological parameters and patient outcome. BMC Cancer 14: 602, 2014.

43. Maeda N, Yoshimura K, Yamamoto S, Kuramasu A, Inoue M, Suzuki N, Watanabe Y, Maeda Y, Kamei R, Tsunedomi R, et al: Expression of B7-H3, a potential factor of tumor immune evasion in combination with the number of regulatory $T$ cells, affects against recurrence-free survival in breast cancer patients. Ann Surg Oncol 21 (Suppl 4): S546-S554, 2014.
44. Baral A, Ye HX, Jiang PC, Yao Y and Mao Y: B7-H3 and B7-H1 expression in cerebral spinal fluid and tumor tissue correlates with the malignancy grade of glioma patients. Oncol Lett 8: 1195-1201, 2014.

45. Ingebrigtsen VA, Boye K, Tekle C, Nesland JM, Flatmark K and Fodstad O: B7-H3 expression in colorectal cancer: nuclear localization strongly predicts poor outcome in colon cancer. Int $\mathrm{J}$ Cancer 131: 2528-2536, 2012.

46. Yamato I, Sho M, Nomi T, Akahori T, Shimada K, Hotta K, Kanehiro H, Konishi N, Yagita H and Nakajima Y: Clinical importance of B7-H3 expression in human pancreatic cancer. $\mathrm{Br}$ J Cancer 101: 1709-1716, 2009.

This work is licensed under a Creative Commons Attribution-NonCommercial-NoDerivatives 4.0 International (CC BY-NC-ND 4.0) License. 